\title{
TECNOLOGIAS SOCIAIS APLICADAS A POLÍTICA NACIONAL DE RESÍDUOS SÓLIDOS: GESTÃO INTEGRADA DE RESÍDUOS SÓLIDOS NO CAMPO
}

\section{SOCIAL TECHNOLOGY APPLY TO NATIONAL POLICY ON SOLID WASTE: SOLID WASTE MANAGEMENT INTEGRATED IN THE COUNTRYSIDE}

\author{
${ }^{1}$ Greice Kelly Lourenco Porfirio de Oliveira \\ ${ }^{2}$ Nivaldo dos Santos
}

\section{RESUMO}

O presente artigo objetiva o estudo das Tecnologias Sociais ambientalmente amigáveis através de técnicas adequadas ao tratamento dos resíduos sólidos descartados de forma inadequada. Após exposição de conceitos, será feita uma reflexão acerca da utilização das Tecnologias Sociais como mecanismo de efetivação dos objetivos de gestão integrada de resíduos traçados pela Política Nacionais Resíduos Sólidos-12.305/10. Por fim, dados da Fundação Banco do Brasil de Tecnologias Sociais serão expostos demonstrando os resultados da utilização de uma tecnologia para promoção da gestão integrada de resíduos sólidos em comunidades rurais de Crateús/CE, por meio de um objetivo disposto na PNRS, coleta seletiva.

Palavras-chave: Tecnologias sociais, Resíduos sólidos, Política nacional de resíduos sólidos

\begin{abstract}
This article aims to study the environmentally friendly social technologies through appropriate techniques to the treatment of solid waste disposed of improperly. After exposure of concepts, a reflection on the use of social technologies as a mechanism for realization of integrated management objectives of waste set by the National Solid Waste Policy will be made $-12.305 / 10$. Finally, data from the Social Technologies Bank of Brazil Foundation will be displayed showing the results of the use of technology to promote the integrated management of solid waste in rural communities Crateús/CE, through a provision aimed at PNRS, selective collection
\end{abstract}

Keywords: Social technologies, Solid waste, National policy on solid waste

\footnotetext{
${ }^{1}$ Mestranda em Direito Agrário pela Universidade Federal de Goiás - UFG, Goiás (Brasil). Professora de Direito Autoral pela Universidade Federal de Goiás - UFG, Goiás (Brasil). E-mail: greicekellylpo@gmail.com

${ }^{2}$ Doutor em Direito pela Pontifícia Universidade Católica de São Paulo - PUC, São Paulo (Brasil). Professor pela Universidade Federal de Goiás - UFG, Goiás (Brasil). E-mail: nivaldo.santos@ pesquisador.cnpq.br
} 


\section{Introdução}

No atual modelo de produção, a problemática voltada ao descarte inadequado e desenfreado dos resíduos sólidos se agrava constantemente em decorrência do crescimento populacional e do consumo e produção cada vez mais acelerados.

A atividade produtiva em larga escala das indústrias e os preceitos capitalistas estimulam cada vez mais o consumismo exacerbado da população. Tal atitude impacta diretamente no meio ambiente, visto que, o aumento da produção e consumo de produtos, resulta no acúmulo de resíduos sólidos os quais são descartados de forma inadequada na natureza.

Em decorrência de uma preocupação mundial, o debate acerca do descarte inadequado dos resíduos, fora apresentado em discussão pela Agenda 21 na Conferência das Nações Unidas, Eco-92 ou Rio-92, propondo um planejamento quanto a forma de produção e consumo sustentáveis visando evitar o desperdício e estabelecendo uma gestão dos resíduos.

Como forma regulatória para o impasse, no Brasil, em 02 de agosto de 2010, se instituiu a lei 12.305, denominada Política Nacional de Resíduos Sólidos- PNRS.

Após o estabelecimento da PNRS, o obstáculo atual é dar efetividade às metas e aos objetivos da mesma, minimizando os impactos ambientais ocasionados pela produção desordenada de resíduos e atendendo as necessidades socioeconômicas do país.

Dentre as questões abarcadas pela Lei $12.305 / 2010$, sob o ponto de estudo da presente pesquisa, destaca-se a necessidade de gestão e gerenciamento de resíduos sólidos, onde deverá ser observada a seguinte ordem de prioridade: não geração, redução, reutilização, reciclagem, tratamento de resíduos sólidos e disposição final ambientalmente adequada dos rejeitos, se restringindo a aplicabilidade de tecnologias sociais ao campo.

Nesse contexto, supõe-se por meio do presente estudo que tecnologias sociais as quais tratam-se de processos inovadores referentes a articulações coletivas de métodos envolvendo tecnologia e arranjos sociais, seriam capazes de técnicas adequadas ao tratamento dos resíduos sólidos, atendendo as determinações contidas na Lei 12.305/10, Política Nacional de Resíduos Sólidos.

Para alcançar resposta a partir da problemática apresentada, pontos serão traçados durante o desenvolver do trabalho com fito de encontrar desdobramentos voltados às tecnologias sociais aplicadas aos preceitos legais descritos na Política Nacional de Resíduos Sólidos. Inicialmente será traçando uma ótica geral sobre o tema, sendo posteriormente 
apresentado um exemplo concreto de tecnologia social aplicado em 14 comunidades rurais do município de Crateús/CE.

Neste sentido, o incentivo por meio de políticas públicas para inserção, divulgação e disponibilização de tecnologias que possibilitem a inclusão social atingindo diversas camadas sociais fazendo interface com a sustentabilidade e os objetivos traçados na PNRS, seriam capazes de realizar ações voltadas à busca de soluções para destinação adequada dos resíduos sólidos?

O estudo busca apresentar soluções que harmonizem o crescimento tecnológico e econômico do pais bem como a proteção ao meio ambiente. Nesse cenário levanta-se como hipótese geral da pesquisa se o incentivo à identificação e aplicação de novas tecnologias sociais as quais possibilitem o uso de inovações que envolvam os conhecimentos e a cooperação social, para promoção de uma gestão integrada de resíduos sólidos nas comunidades rurais, através de mecanismos que propiciem o descarte adequado, a reutilização dos rejeitos bem como sua transformação em fonte de renda para a população, atribui aplicabilidade e efetivação a normatização disposta na Lei 12.305/10, como forma de conter o desgaste do campo e para toda a sociedade, evitando a existência de degradações ambientais causadas pela destruição dos recursos naturais decorrentes do manejo/descarte inadequado dos resíduos sólidos.

Tal hipótese possibilita a efetiva vivência de sustentabilidade agrária entre coletividade e agentes produtivos, contribuindo ainda de forma significante para o desenvolvimento econômico e tecnológico nacional.

O presente trabalho está disposto em três passagens que nortearão a perseguição do proposto: em primeiro momento, tratar-se-á da Tecnologia Social não apenas como adjetivo social utilizado nos países subdesenvolvidos, mas também como crítica ao atual modelo de desenvolvimento tecnológico utilizado. Assim, será proposto no presente tópico uma condição mais sustentável e solidária das técnicas visando atender as necessidades de preservação/conservação do meio ambiente.

Em segundo ponto será apresentada a Lei 12.305/10, denominada Política Nacional dos Resíduos Sólidos, tratada como principal marco regulatório no que tange à gestão de resíduos, e propõe uma gestão integrada de resíduos sólidos. E por fim, em um terceiro ponto, serão demonstrados por meio de um estudo comparado a maneira como as atividades realizadas com tecnologia social de gestão integrada de resíduos sólidos desenvolvida em 14 comunidades do Crateús contribuíram de forma efetiva a implantação das metas traçadas 
pela Politica Nacional de Resíduos Sólidos no setor agrícola minimizando os impactos dos resíduos sólidos.

\section{Tecnologias Sociais e sustentabilidade}

A partir das últimas décadas no Brasil, a proposta de inserção de tecnologias que possibilitem a inclusão social vem sendo cada vez mais difundida, ao passo que, surge o termo "tecnologia social". Tal expressão deve ser vista de forma ampla a atingir diversas camadas sociais.

Muitos conhecem, contudo, apenas alguns conseguem distinguir de fato o que são tecnologias sociais (TSs). Tais métodos estão por toda parte, e são muito simples, todavia, nem sempre recebem o status de tecnologia.

Como bem explana Jesus e Costa (2013, p. 18), “o adjetivo social não tem a pretensão de afirmar somente a necessidade de tecnologia para os pobres ou países subdesenvolvidos. Também faz crítica ao modelo convencional de desenvolvimento tecnológico”. Assim, para os autores, a tecnologia social propõe uma condição mais sustentável e solidária das técnicas.

Portanto, a pluralidade de saberes e práticas sociais começam a repercutir no conhecimento da ciência moderna, para (SOUZA SANTOS, 2004, p. 21):

a diversidade epistemológica do mundo, a pluralidade conflitual de saberes que informam as práticas sociais e o modo como ela repercute no questionamento epistemológico da ciência moderna em geral, e das ciências sociais em particular.

Sousa Santos (2004, p. 21) elucida ainda que o desenvolvimento tecnológico entrou em colapso com outras técnicas e formas de conhecimento, as quais para o autor "privilegiavam a busca do bem e da felicidade ou da continuidade entre sujeito e objeto, entre natureza e cultura, entre homens e mulheres e entre seres humanos e todas as outras criaturas", portanto em suma, existem conhecimentos para além dos conhecimentos científicos.

Como sabiamente explanou SANTOS (2000, p. 62), estão presentes em todos os comportamentos do homem para com a natureza, técnicas as quais foram se aprimorando, diversificando ao longo do tempo. " As técnicas oferecem respostas à vontade de evolução dos homens e são definidas pelas possibilidades que criam, são as marcas de cada período da história". 
Jacobi (2003) já preconizava o desenvolvimento pautado na sustentabilidade sócio ambiental, o qual deve promover a integração do meio natural e do social, inserindo ainda análise determinantes do processo, considerando o papel de diferentes atores envolvidos assim como as "formas de organização social que aumentam o poder das ações alternativas".

Assim, tal necessidade voltada às questões inerentes ao desenvolvimento sustentável e sócio ambiental possibilitaram a evolução do conceito de tecnologia social.

Bava (2004, p.116), propõe a seguinte definição de tecnologias sociais:

Mais do que a capacidade de implementar soluções para determinados problemas, podem ser vistas como métodos e técnicas que permitam impulsionar processos de empoderamento das representações coletivas da cidadania para habilitá-las a disputar, nos espaços públicos, as alternativas de desenvolvimento que se originam das experiências inovadoras e que se orientam pela defesa dos interesses das maiorias e pela distribuição de renda.

Portanto, as tecnologias sociais referem-se a um processo de inovação o qual conta com articulações coletivas para métodos que envolvam tecnologias, arranjos sociais bem como distribuição da renda auferida com os lucros.

Podem ser estabelecidos por meio das Tecnologias Sociais um vinculo entre o saber popular, organização social e o conhecimento técnico-científico. Sendo imprescindível apenas, que sejam métodos efetivos e reaplicáveis (BANCO DO BRASIL, 2004).

É importante ainda apresentarmos o conceito transformador atribuído às tecnologias sociais pela Rede de Tecnologia Social (RTS): "Tecnologia Social compreende produtos, técnicas e/ou metodologias reaplicáveis, desenvolvidas na interação com a comunidade e que represente efetivas soluções de transformação social."

Para uma aplicabilidade efetiva de tais tecnologias e medidas sustentáveis, são necessárias soluções eficientes de modelos de governanças através de políticas públicas eficientes no sentido de analisar as condições para operacionalização social, política e tecnológica do desenvolvimento sustentável por meio de intervenção do poder público e da sociedade, objetivando a preservação dos interesses comuns de preservação da vida como um todo no planeta (MORIN; KERN, 2011).

Nesse diapasão, métodos inéditos podem ser difundidos, e valorizados possibilitando a construção de novos paradigmas por meio de novos atores sociais, propiciando ainda um fortalecimento da democracia e da cidadania, bem como uma melhoria na qualidade de vida da população em geral. 
É importante ponderar que assim como as tecnologias sociais, o desenvolvimento sustentável surge sobre a premissa de conter os impactos ambientais implantados no costume popular pelos modos adotados desde a colonização, bem como as consequências decorrentes do conhecimento tecnológico e cientifico "inconsequente".

Assim surge o conceito de desenvolvimento sustentável, o qual visa alinhar o desenvolvimento industrial, tecnológico, e econômico com o meio ambiente, objetivando preservá-lo para as futuras gerações.

Portanto, sob tal perspectiva podemos observar que as tecnologias sócias, apresentam-se como medias sustentáveis, como bem ponderou Guerra (2012, p. 107), o desenvolvimento sustentável ampara-se em três pontos: o econômico, ambiental e social:

Evidencia-se, pois que o princípio do desenvolvimento sustentável encontra-se ancorado em três pontos fundamentais: o econômico, o social e o ambiental. Assim, o desenvolvimento sustentável deve contemplar: a sustentabilidade econômica, que implica a alocação e gestão mais eficientes dos resíduos públicos e privados, com eliminação de barreiras protecionistas entre os países, a oportunização de tecnologias e a avaliação de eficiência econômica em termos macrossociais; a sustentabilidade ecológica, que pressupõe a racionalização dos recursos naturais, a limitação de usos de bens esgotáveis ou potencialmente poluidores, a utilização de tecnologia ecológicas e outras medidas.

Assim, dentro das hipóteses levantadas no presente estudo, as tecnologias sociais apresentam-se como instrumento sustentável na gestão dos resíduos viabilizando o tratamento dos resíduos que são descartados diariamente no meio ambiente sem quaisquer tratamentos, compatibilizando a atividade econômica como a proteção do meio ambiente.

Lemos (2012, p. 50) demonstra a necessidade de adotar o princípio do desenvolvimento sustentável na gestão dos resíduos, segundo a autora, significa utilizar um conjunto de instrumentos preventivos visando harmonizar a atividade econômica e o desenvolvimento com proteção ao meio ambiente.

Contudo, como forma de demonstrar a viabilidade das tecnologias sociais sob o aspecto da governança, será traçado nos próximos pontos preceitos estabelecidos em uma Política Pública, os quais são atendidos através de tecnologia social. Para o estudo em questão serão abordados pontos da Lei 12.305/2010 denominada Política Nacional de Resíduos Sólidos, associada a dados da Fundação Banco de Tecnologias Sociais, os quais demonstram a efetividade de uma tecnologia social inerente a "gestão integrada de resíduos sólidos em comunidades rurais de Crateús/CE, por meio de um metas traçadas pela PNRS, coleta seletiva, gestão integrada de resíduos, dentre outros. 


\section{Política Nacional de Resíduos Sólidos - Lei 12.305/10}

No atual modelo econômico o meio ambiente sempre fora relacionado ao "campo de externalidade" do sistema, possibilitando uma ameaça crescente de um colapso socioambiental, bem como a escassez de recursos naturais, fator que fora denominado por Beck (2002, p. 84) como "sociedade de risco".

A problemática dos resíduos é potencializada em decorrência do crescimento populacional e seu consumo desenfreado. Assim, a sociedade atual é nomeada como sociedade de consumo (LIPOVETSKY, 2007).

A história dos resíduos sólidos se confunde com a história da humanidade, como bem demonstrou Philippi: "a partir do momento em que os homens começaram a se estabelecer em determinados locais, preferindo se fixar, com consequente abandono da vida nômade, novas situações em relação aos resíduos sólidos produzidos pelas atividades humanas foram criadas pelas alterações introduzidas em seus hábitos de vida" (PHILIPPI, 1979. p.222).

Nessa perspectiva, Patrícia Reis elucida que o meio ambiente não está conseguindo se recuperas naturalmente dos impactos sofridos decorrentes do desgaste desordenado. Décadas após décadas, consome-se dele mais do que o mesmo pode nos oferecer, e o caminho mais plausível segundo a autora é o despertar e provocar a conscientização e ações eficientes no combate a ameaça da escassez dos recursos naturais e da degradação ambiental (REIS, 2013).

Diante disso, nas ultimas décadas um despertar mundial para as questões relacionadas ao meio ambiente vem se concretizando e readequando as condições ambientais as quais de forma gradativa estão sendo introduzidas no cotidiano da população. Nesse diapasão, podemos citar o descarte inadeadequado dos resíduos, debate que foi submetido em discussão pela Agenda 21 na Conferência Eco-92 ou Rio-92, propondo um planejamento quanto a forma de produção e consumo sustentáveis evitando o desperdício, estabelecendo uma gestão dos resíduos.

A partir desta realidade, se obteve grande respaldo legislativo na tentativa de diminuir e se possível eliminar os riscos decorrentes da produção desenfreada de resíduos sólidos. Como marco fundamental legislativo garantidor de um ambiente equilibrado e ao 
desenvolvimento sustentável, podemos citar o artigo 225, Caput da Constituição Federal de $1988^{1}$, tendo, portanto o status de direito fundamental da coletividade e do indivíduo.

Tal medida estabelecida pela Constituição Federal de 1988 segundo Leite (2010, p. 222) "é a mais avançada e moderna porquanto repele a proteção ambiental em função do interesse exclusivo do homem para dar lugar à proteção em função da ética antropocêntrica alargada".

Nessa linha de pensamento ponderam Sarlet e Fensterseifer (2011, p. 181/182), que a Constituição de 1988, consagrou a proteção ambiental e o desenvolvimento sustentável como um dos objetivos ou tarefas fundamentais do Estado Socioambiental de Direito Brasileiro. Assim, segundo os autores, existe um duplo escopo que se reflete como um objeto e tarefa estatal e ao mesmo tempo como um direito/e dever fundamental do indivíduo e da coletividade, implicando todo um grupo de direitos e deveres fundamentais de caráter ecológico, restando caracterizado o dever do Estado de providenciar meios - legislativos e administrativos, inerentes à tutela ecológica.

Diante disso, buscando alcançar preceitos estabelecidos pela norma constitucional fundamental, em especial no que tange a gestão de resíduos, 02 de agosto de 2010, foi estabelecida no Brasil a Política Nacional de Resíduos Sólidos- PNRS (Lei 12.305/10) regulamentada pelo Decreto 7.404/2010.

Segundo Bellingieri (2012, p. 527), este é o principal marco regulatório brasileiro a respeito da gestão de resíduos, uma vez que o legislador se preocupou segundo o autor, não só em definir instrumentos é metas para a gestão do lixo, mas também em mostrar que a PNRS nasce marcada pela premissa do desenvolvimento sustentável.

Contudo, em que pese importante marco legislativo, este não atendeu de forma imediata o compromisso político contido no Capítulo 21, da Agenda 21, decorrente da Conferência das Nações Unidas para sobre o Meio Ambiente e o Desenvolvimento - Rio/92, vejamos:

O manejo ambiental saudável desses resíduos deve ir além do simples depósito ou aproveitamento por métodos seguros dos resíduos gerados é buscar resolver a causa fundamental do problema, procurando mudar os padrões não sustentáveis de produção e consumo. Isso implica na utilização do conceito de manejo integrado do ciclo vital o qual apresenta oportunidade única de conciliar o desenvolvimento com a proteção do meio ambiente (NAÇÕES UNIDAS, 1992).

\footnotetext{
${ }^{1}$ Art. 225 CF- Todos têm direito ao meio ambiente ecologicamente equilibrado, bem de uso comum do povo e essencial à sadia qualidade de vida, impondo-se ao Poder Público e à coletividade o dever de defendê-lo e preservá-lo para as presentes e futuras gerações.
} 
Dentre as inovações trazidas pela Lei, sob o ponto de abordagem que se pretende pesquisar, se destaca a necessidade de gestão e gerenciamento de resíduos sólidos, onde deverá ser observada a seguinte ordem de prioridade: não geração, redução, reutilização, reciclagem, tratamento de resíduos sólidos e disposição final ambientalmente adequada dos rejeitos. Vale pontuar que a pesquisa se restringirá ao setor agrícola e a tecnologias sociais.

Segundo orientações expressas na Agenda 21 - Rio/92 (NAÇÕES UNIDAS, 1992), o tratamento de resíduos conforme já vem sendo implantado por outros países, preconiza obrigatoriedade na gestão e no gerenciamento do lixo, priorizando a seguinte ordem hierárquica: não gerar, reduzir, reutilizar, reciclar, tratar e dispor adequadamente os rejeitos, conforme disposto no artigo $9^{\text {a }}$ da Lei:

Art. $9^{\circ}$. Na gestão e gerenciamento de resíduos sólidos, deve ser observada a seguinte ordem de prioridades: não geração, redução, reutilização, reciclagem, tratamento dos resíduos sólidos e disposição final ambientalmente adequada dos rejeitos.

Machado (2013, p. 634) demonstra que a PNRS apresenta uma sequência de prioridades na gestão e gerenciamento dos resíduos sólido.

Para auferir a importância da Lei 12.305/2010, podemos citar os dizeres de Édis Milaré (2011, p. 855)
A Política Nacional de Resíduos Sólidos preencheu uma importante lacuna no arcabouço regulatório nacional. Essa iniciativa é o reconhecimento, ainda que tardio, de uma abrangente problemática ambiental que assola o País, problemática esta de proporções desconhecidas, mas já com diversos episódios registrados em vários pontos do território nacional, e que tem origem exatamente na destinação e disposição inadequada de resíduos e consequente contaminação no solo, além da dificuldade de identificação dos agentes responsáveis.

Segundo Amado (2014, p.723), considera-se resíduo sólido o material, substância, objeto ou bem descartado proveniente de atividades humana em sociedade, cuja destinação final se procede ou está obrigada a proceder, nos estados sólidos ou semissólidos, bem como gases contidos em recipientes e líquidos cujas particularidades tornem inviável o seu lançamento na rede pública de esgotos ou em corpos d'agua, ou exijam para isso soluções técnicas ou economicamente inviáveis em face da melhor tecnologia disponível.

Como forma de aplicabilidade da Lei, estabeleceram-se regras de transição as quais objetivando atender ao Princípio da Segurança Jurídica, determinaram para alguns 
dispositivos da Lei o prazo de vacância de até 4 (quatro) anos após a data de publicação, a qual ocorreu em 03/08/2010.

Ao conceituar a gestão integrada dos resíduos a Lei 12.305/2010 em seu artigo $3^{\circ}$, IX estabelece ser o conjunto de medidas direcionadas à busca de soluções para os resíduos sólidos, considerando os aspectos políticos, econômicos, culturais e sociais, com controle social sob a perspectiva do desenvolvimento sustentável.

Nesse diapasão, a necessidade do desenvolvimento sustentável também é apresentada por meio da definição legal de padrões sustentáveis de produção e consumo, as quais são elencadas no artigo $3^{\circ}$, XIII da Lei $^{2}$, visando atender as necessidades das futuras gerações.

Contudo, apesar dos preceitos legais e prazos para cumprimento, o discurso desenvolvimentista ainda aparece de forma contraposta à proteção do meio ambiente.

Liebmann (1979, p. 177), em seu livro intitulado Ein Planet Wird Unberwohnbar (“Terra um planeta inabitável?", no título traduzido livremente para o português), publicado na Alemanha, alerta para a necessidade de equilibrar conjuntamente a ecologia e a economia, considerando os interesses opostos de ambos os componentes, como "dois pratos de uma balança, mas ciente de que disso depende a sobrevivência da humanidade".

Atualmente, o desafio que se impõe após o estabelecimento da PNRS é dar aplicabilidade aos conceitos, metas e objetivos da Lei, minimizando os impactos ambientais ocasionados pela produção de resíduos, vez que o prazo estabelecido escoou em agosto de 2014.

Como bem pontuou Donaire (1995), existem diferentes constantes que afetam o ambiente dos negócios, sendo que a cada dia a preocupação social tem se destacado diante de sua nítida real importância para a vida da sociedade. Para tanto, é preciso se conscientizar que a proteção ambiental não caminha em desencontro ao desenvolvimento econômico nacional.

Assim, como proposta de harmonizar o desenvolvimento sustentável e o tecnológico com fito de efetivar o direito fundamental ao meio ambiente equilibrado e vivência da sustentabilidade, o presente estudo propõe a demonstrar no próximo ponto uma forma de gestão integrada de resíduos sólidos produzidos por comunidades rurais, como forma de efetivação de alguns preceitos traçados pela Política Nacional de Resíduos Sólidos, por meio de tecnologias sociais.

\footnotetext{
${ }^{2}$ Lei 12.305/2010 - Artigo $3^{\circ}$, XIII: padrões sustentáveis de produção e consumo: produção e consumo de bens e serviços de forma a atender as necessidades das atuais gerações e permitir melhores condições de vida, sem comprometer a qualidade ambiental e o atendimento das necessidades das gerações futuras.
} 


\title{
3 Sistema de Gestão Integrada de Resíduos Sólidos: Comunidades Rurais de Crateús/CE
}

Como sabiamente alertou Souza Santos (2004, p. 25), o retorno a uma atitude incisiva de questionamento e debate sobre a aplicação de "diferentes saberes" é hoje uma necessidade urgente, preconizando ainda:

\begin{abstract}
O próprio desenvolvimento tecnológico e os problemas que criadas questões éticas e políticas decorrentes das novas fronteiras da biotecnologia e dos novos problemas da saúde pública aos impactos ambientais sanitários, econômicos e políticos das sementes transgênicas, do uso de fertilizantes tóxicos ou da construção de grandes barragens - nos obrigam a enfrentar os desafios de envolver de maneira construtiva nos debate e na pesquisa de soluções todos os atores que direta ou indiretamente estejam ligados a esses problemas. Tal atitude exige a abertura a um questionamento mais amplo e profundo e uma participação mais alargada e informada no debate, por forma a constituir uma rede de intervenção em que todas as formas de conhecimento possam construtivamente participar em função da sua relevância para a situação em causa (SOUZA SANTOS, 2004. p. 25).
\end{abstract}

Atualmente, conforme exposto anteriormente, vivemos em uma crise ambiental em decorrência do constante aumento populacional, aliado ao modelo de desenvolvimento econômico o qual explora as bases naturais objetivando a constante ampliação dos níveis de consumo. Assim, nesse cenário, em decorrência do alto índice de resíduos sólidos, cada vez mais estes são descartados de forma inadequada no meio ambiente.

Morin e Kern, (2011, p. 160) demonstram a necessidade de inserção de um novo paradigma de conhecimento o qual considere a economia, ecologia, bem como demais aspectos ligados a tais áreas como demografia, cultura e biodiversidade em termos planetários. Contudo, para os autores é importante impor uma maneira de pensar diferente.

Nessa perspectiva, a tecnologia social de gestão integrada de resíduos sólidos desenvolvida em comunidades rurais de Crateús/CE por meio de coleta seletiva, compostagem e reaproveitamento dos resíduos sólidos, estabelece no município uma situação garantidora de renda para a população propiciando ainda um ambiente mais saudável à todos e qualidade de vida aos beneficiários.

Segundo informações extraídas do sistema de Tecnologia Sociais da Fundação Banco do Brasil (2014), a tecnologia social de gestão integrada de resíduos sólidos, possui como tema principal a relação do homem com o meio ambiente e se originou em decorrência da ausência de local adequado para destinação dos resíduos das comunidades rurais do entorno da Reserva Natural Serra das Almas no Município de Crateús/CE. Todos 
os rejeitos eram descartados a "céu aberto", nos rios ou ate mesmo enterrados de forma inapropriada nos próprios quintais ou proximidades das casas dos moradores rurais. Outra prática também inadequada que era realizada nas comunidades eram as queimadas dos lixos.

Assim, como objetivo geral da tecnologia social, visando conter os enormes danos ocasionados no meio ambiente oriundos de tais práticas incorretas de descarte de resíduos, fora proposta a implantação de gestão participativa dos resíduos sólidos em 14 comunidades rurais do entorno da Reserva Natural Serra das Almas, com a instituição de "sistema integrado de reaproveitamento e destinação adequada dos resíduos produzidos, promovendo melhorias na qualidade de vida e ambiental da região" (BANCO DO BRASIL, 2014).

Por meio de tal medida se objetivava promover a conscientização da população das comunidades rurais acerca da importância da separação e gestão dos resíduos sólidos, a diminuição dos impactos ambientais sobre a água, solo e ar decorrentes da destinação incorreta do lixo, geração de renda para os envolvidos por meio da comercialização de compostos orgânicos, contribuir para o desenvolvimento comunitário no engajamento dos problemas ambientais e envolvimento o poder público por meio de políticas públicas para gestão dos resíduos sólidos das áreas rurais (BANCO DO BRASIL, 2014).

Para inserção da tecnologia social na comunidade de Crateús/CE, foram realizadas oficinas de educação envolvendo jovens, mulheres e agricultores. No evento foram repassadas informações de separação e distinção do material não reciclável do reciclável bem como tipos de resíduos. Posteriormente, os próprios moradores começaram a separar os lixos secos dos úmidos os quais eram levados para armazenamento de 30 coletores, sendo posteriormente transformados em adubos orgânicos. Em relação ao material seco, se firmou uma parceria com a prefeitura municipal para transporte dos materiais recicláveis os quais foram doados para a Associação de Catadores de Crateús - Recicratiú, momento em que os resíduos foram reciclados e retornaram para o mercado como matérias primas. (BANCO DO BRASIL, 2014).

Dentre os resultados alcançados podemos citar como principal a implantação do primeiro Sistema de Gestão de Resíduos localizado na zona rural do município de Crateús/CE, beneficiando de forma direta segundo dados extraídos da Fundação de Tecnologia Social do Banco do Brasil (2014), cerca de 2.000 (duas mil) pessoas, além da melhoria na qualidade do meio ambiente o que acaba por favorecer de forma indireta todos os moradores da região. Seguem outros resultados decorrentes da tecnologia de gestão integrada: 
Por mês, são retiradas cerca de 2 toneladas de resíduos das comunidades rurais para serem recicladas e reintroduzidas na cadeia produtiva comercial o que representa um incremento de $17 \%$ no volume de material que era coletado mensalmente pela Associação de Catadores de Crateús - Recicratiú. Em consequência, são beneficiados 12 associados, que são responsáveis pela realização das tarefas de coleta e triagem do material. Através da disseminação de técnicas de compostagem, 75 pessoas passaram a produzir compostos orgânicos, que são utilizados no cultivo de seus alimentos. Com a produção do composto, os agricultores ampliaram e diversificaram a produção, incluindo hortas e mandalas, que são enriquecidas por esse produto e tem o seu excedente comercializado. $\mathrm{O}$ excedente do composto orgânico que não é utilizado no cultivo também é comercializado entre os produtores juntamente com os alimentos, configurando-se como uma fonte de renda sustentável para os agricultores. Até o hoje, foram arrecadados 2.600 reais com a venda do composto orgânico. No semiárido, o aproveitamento de resíduos orgânicos pela compostagem é um processo chave para manutenção e conservação da fertilidade dos solos, sendo uma alternativa viável e de baixo impacto se comparada a agricultura familiar tradicional. Com a mobilização social e ações de educação ambiental foram atingidas diretamente 491 pessoas, que participaram 15 oficinas e capacitações. As pessoas que antes não tinham solução para a questão do lixo, hoje podem reutilizá-los de forma adequada com o mínimo de impacto e possibilitando a geração de renda. Esse modelo integrado e participativo de gestão de resíduos está sendo disseminado e pretende ser ampliado para outras comunidades do município de Crateús (BANCO DO BRASIL, 2014).

Portanto, diante da experiência realizada na comunidade rural de Crateús no Estado do Ceará, pode-se constatar que meio de conhecimentos e técnicas que envolvam a cooperação social e o meio ambiente é possível realizar a gestão integrada de resíduos sólidos promovendo assim a efetividade de preceitos e metas traçadas pela Política Nacional de Resíduos sólidos, bem como às garantias constitucionais dispostas no artigo 225 que garantem a todos e as futuras gerações um meio ambiente limpo e saudável.

\section{Conclusão}

O objetivo geral do presente estudo foi a análise acerca da aplicabilidade das tecnologias sociais na gestão sustentável dos resíduos sólidos produzidos em comunidades agrícolas.

Ao se levantar como hipótese geral da pesquisa o incentivo à identificação e aplicação de novas tecnologias sociais as quais apresentem inovações envolvendo conhecimentos tradicionais e cooperação social como um todo, objetivando uma gestão integrada de resíduos sólidos nas comunidades rurais, visando a utilização de técnicas que 
proporcionem o descarte adequado, reutilização dos rejeitos bem como sua transformação em fonte de renda para a comunidade, verificou-se de acordo com os pontos apresentados pelos autores ao longo do estudo, bem como com os dados auferidos da Fundação de Tecnologia Social do Bando do Brasil (2014) por meio do Sistema de Gestão Integrada de Resíduos implantado na zona rural do município de Crateús/CE, que as tecnologias sociais possibilitam uma real e efetiva vivência de sustentabilidade, no que tange a satisfação dos preceitos abarcados pela Política Nacional de Resíduos Sólidos - Lei 12.305/2010.

Assim, a utilização da tecnologia social utilizada pela comunidade rural de Crateús/CE, proporcionou benefícios aos diretamente envolvidos no programa visto que todos os recicláveis são reintroduzidos na cadeia produtiva comercial, e os demais dejetos são transformados em adubos orgânicos. Portanto, verifica-se que além dos benefícios diretos à cerca de 2.000 (duas mil) pessoas, tal gestão integrada dos resíduos sólidos proporciona melhoria na qualidade de todo o meio ambiente e acaba por favorecer de forma indireta todos os moradores da região, bem como à garantir o direito constitucional das futuras gerações.

Em relação as tecnologias sociais, é importante constar a necessidade da pluralidade dos saberes e práticas sociais sustentáveis terem repercussão no conhecimento e desenvolvimento da ciência moderna, contribuindo de forma real e efetiva no cumprimento das governanças implantadas para inibir impactos causados pelo consumismo desenfreado e descarte indevido dos resíduos sólidos.

Nesse diapasão, a Política Nacional de Resíduos Sólidos representa um forte avanço na proteção e preservação do meio ambiente, contudo, possui o desafio de que seja efetivamente executada e cumprida, ao passo que, a conciliação de novas formas democráticas de participação social distante de preconceitos, mitos ou paradigmas através de parcerias com cooperação entre o poder público, refere-se ao começo de um processo de conscientização e efetiva implantação das metas e objetivos da Lei 12.305/10.

Ainda que nascente, o passo dado pela comunidade de Crateús/CE é um claro sinal de uma importante mudança para a sociedade brasileira, demonstrando que as técnicas desenvolvidas por meio da comunidade são eficazes e capazes de atenderem aos preceitos do desenvolvimento e de soluções sustentáveis as quais atendem também os objetivos da Política Nacional de Resíduos Sólidos - Lei 12.305/2010. 


\section{Referências Bibliográficas}

AMADO, Frederico. Direito Ambiental Esquematizado. 5ª Ed. Método. 2014. P 723.

BANCO DO BRASIL, Fundação, Banco de Tecnologias Sociais. Lixo e Transformação socioambiental: Gestão Integrada de Resíduos Sólidos. Disponível em: $<$ http://www.fbb.org.br/tecnologiasocial/banco-de-tecnologias-sociais/pesquisartecnologias/detalhar-tecnologia-106.htm>. Acesso em 27 mar 2016.

BANCO DO BRASIL, Fundação. Tecnologia social: uma estratégia para o desenvolvimento. Rio de Janeiro: Fundação Banco do Brasil, 2004.

BAVA, Silvio C. Tecnologia social e desenvolvimento local. In: FUNDAÇÃO BANCO DO BRASIL (org.) Tecnologia social: uma estratégia para o desenvolvimento. Rio de Janeiro: FBB, 2004. p.103-16

BELLINGIERI, Paulo Henrique. Sistema de informação sobre resíduos sólidos como instrumento de gestão. 2012. P.527.

BRASIL. Constituição da República Federativa do Brasil de 1988. Disponível em: http://www.planalto.gov.br/ccivil_03/constituicao/ConstituicaoCompilado.htm. Acesso em 22 Mar 2014.

. Lei 12.305/2012. Política Nacional dos Resíduos Sólidos. Disponível em: http://www6.senado.gov.br/sicon/ExecutaPesquisaBasica. Acesso em: 28 de mar 2016.

BECK, U. La sociedade del riesgo. Madrid: Paidós, 1998.

Congresso de Gestão de Tecnologia Latino-Iberoamericado - ALTEC 2013, disponível em: http://www.altec2013.org/programme_pdf/1518.pdf . Acesso em 22 mar 2016.

DONAIRE D. Gestão ambiental na empresa. São Paulo, SP. Ed. Atlas, 1995.

GUERRA, Sidney. Resíduos sólidos: Comentários à Lei 12.305/2010. Rio de Janeiro: Forense, 2012.

JACOBI, P. Educação ambiental, cidadania e sustentabilidade. Cadernos de pesquisa. N. 118, março/ 2003.

LIEBMANN, Hans. Terra um planeta inabitável? Da antiguidade até nossos dias, toda a trajetória poluidora da humanidade. Rio de Janeiro, 1979. P 177.

LIPOVETSKY, Gilles. A felicidade paradoxal: ensaio sobre a sociedade de hiperconsumo. São Paulo: Companhia das Letras, 2007.

LEITE, J. R M; FERREIRA, H.S; BORATTI, L V. Estado de Direito Ambiental: tendências. 2 Ed. Rio de Janeiro: Forence Universitária, 2010. 
LEMOS, Patrícia F. I. Resíduos Sólidos e responsabilidade civil pós-consumo. 2. Ed. São Paulo: Pearson, 2009.

MORIN, E; KERN, A. B. Terra - pátria. 6. Ed. Porto Alegre: Sulina, 2011.

NAÇÕES UNIDAS, Conferência. Agenda 21, Capítulo 21. Disponível em: <http://www.mma.gov.br/responsabilidade-socioambiental/agenda-21/item/681>. Acesso em 27 mar 2016.

REDE DE TECNOLOGIA SOCIAL, Disponível em: <http://rts.ibict.br/rts/tecnologiasocial/tecnologia-social>, Acesso em 28 mar 2016

SARLET, Ingo W; FERNSTERSEIFER, Tiago. Direito Constitucional Ambiental: estudos sobre a Constituição, os direitos fundamentais e a proteção do ambiente. São Paulo: Ed. Revista do Tribunais, 2011.

SANTOS, M. Por uma outra globalização: do pensamento único à consciência universal. 3. ed. Rio de Janeiro: Record, 2000.

SOUSA SANTOS, Boaventura de (Org.). Semear outras soluções: os caminhos da Biodiversidade e dos conhecimentos rivais. Porto: Edições Afrontamento, 2004.

PHILIPPI JR A. Sistema de resíduos sólidos: coleta e transporte no meio urbano. São Paulo (SP); 1979. - Dissertação de Mestrado - Departamento de Saúde Ambiental da Faculdade de Saúde Pública da USP. 